\title{
The xanthophyll-cycling pigment dynamics of Isochrysis galbana (Prymnesiophyceae) during light-dark transition
}

\author{
Mitsuko Obata \& Satoru Taguchi* \\ Faculty of Engineering, Soka University, 1-236 Tangi-cho, Hachiouji, Tokyo 192-8577, Japan
}

Received 31 January 2012; Accepted 27 March 2012

\begin{abstract}
We investigated the photoresponses of diadinoxanthin (DD) and diatoxanthin (DT) using Isochrysis galbana cultures that had been acclimated to four different levels of photon flux density (PFD). DD can play a role as a photosynthetic light-harvesting pigment, whereas DT can play a role as a photoprotective pigment. The PFD ranged from limited light conditions (LL) to saturated light conditions (SL) for growth. The photoresponses of these pigments during light-dark transitions at each acclimation PFD were consistent. The photoresponses of these xanthophyll pigments, as normalized to either cell density or chlorophyll $a(\mathrm{Chl} a)$ concentration, to light-dark transitions varied with acclimation PFD. The stoichiometric variations between the DD or DT : Chl $a$ ratio observed at the two higher acclimation PFDs suggested that these xanthophyll dynamics are controlled by xanthophyll cycling processes in addition to de novo processes and interconversion between DD and fucoxnathin under SL conditions. Significant linear relationships were observed between the levels of DD and/or DT normalized to either the cell density or Chl $a$ concentration. Based on the cellular pigment content and the xanthophyll : Chl $a$ ratio, the slopes of the linear relationships normalized to either the cell density or Chl $a$ concentration were significantly related to the acclimation PFD linearly and sigmoidally, respectively. Similarly, the acclimation PFD at the interaction of the sigmoidal change and the transition point from the LL to SL condition suggests that these xanthophyll pigment dynamics can be characterized by acclimation to the light conditions. An examination of the slope may provide information leading to a better understanding of photoacclimation in the algal photosynthetic apparatus.
\end{abstract}

Key words: diadinoxanthin, diatoxanthin, photoacclimation, photon flux density, photoprotection

\section{Introduction}

The aquatic environment has a highly variable photon flux density (PFD), and algal cells are exposed to a range of PFD from 0 to $2000 \mu \mathrm{mol}$ photons $\mathrm{m}^{-2} \mathrm{sec}^{-1}$ in natural conditions (Jerlov 1976, Cullen \& Lewis 1988). The wide range in aquatic PFD is caused by day-night cycles and vertical mixing. The PFD is an important factor in determining the variability in the photosynthetic responses and growth rates of algae (Falkowski 1984, Falkowski \& Dubinsky 1980, Palmisano et al. 1985, Harrison \& Platt 1986, Cullen 1990). The acclimation of algae to the PFD, which is referred to as photoacclimation, follows rules that result in the optimization of photosynthesis within the constraints of the light conditions. This optimization involves a balance between maximizing the rate of photosynthesis

\footnotetext{
*Corresponding author: Satoru Taguchi; E-mail, staguchi@soka.ac.jp
}

under a limiting PFD and minimizing the damage that can arise from saturating or excess PFD (Raven \& Geider 2003). Photoacclimation operates on time scales of hours and days, due to changes in the macromolecular composition and function of the photosynthetic apparatus that occurs in response to the PFD variations. In the context of the light reactions, photoacclimation is accompanied by changes in the composition and cellular abundance of pigments and changes in the electron transfer chain components (for a review, see Falkowski \& La Roche 1991).

Xanthophyll pigments are carotenoids that fulfill both photosynthetic light-harvesting and photoprotective functions in algae, and these pigments are essential for the survival (Polimene et al. 2012) and ecological success of algae in their natural environments (Eonseon et al. 2003). In chlorophyll $c(\mathrm{Chl} c)$-containing algae, such as diatoms, dinoflagellates and prymnesiophyceae, diadinoxanthin (DD) and fucoxanthin (Fuco) can transfer excitation en- 
ergy to chlorophyll $a(\mathrm{Chl} a)$ and play a role in the acquisition of light energy as a photosynthetic light-harvesting pigment, whereas diatoxanthin (DT) can absorb excitation energy from $\mathrm{Chl} a$ and play a role in thermal dissipation as a photoprotective pigment (Shreve et al. 1991, Young et al. 1997, Lohr \& Wilhelm 1999, 2001, Harris et al. 2009, Polimene et al. 2012). The cellular content of Fuco exhibits the same variations as other chlorophyll pigments in response to the PFD intensity, however, the cellular content of DD and DT exhibits variation patterns that are different from other pigments (MacIntyre et al. 2002). The specific dynamics of DD and DT have been reported in previous studies (e.g., Ragni \& D’alcalà 2007). The selective synthesis or degradation of DD and DT are known to be de novo synthesis or degradation processes (Olaizola et al. 1994). In addition to the de novo process, a reversible conversion between DD and DT is known in the xanthophyll cycling process (DD-cycle). The xanthophyll cycling process is one of the main processes regulating excessive light energy in the light-harvesting complexes of photosystems and represents an important photoprotection mechanisms in algae (for a review, see Goss \& Jakob 2010). The conversion of DT to DD occurs under limited PFD and darkness, whereas a reverse conversion occurs under excess PFD. The DD-cycle is controlled by light-dark transition in addition to the PFD intensity (Hager 1980, Yamamoto 1985). Furthermore, an interconversion between Fuco and DD has been proposed in recent reports (e.g., Lohr \& Wilhelm 1999, Harris et al. 2009, Polimene et al. 2012). The interconversion could be reversible depending on light conditions. Because the DD and DT dynamics can be affected by the light-dark transition and the intensity of the PFD, this could be of benefit in the highly variable underwater light climate, which requires high flexibility (Goss \& Jakob 2010). The photoresponse of these xanthophyll pigments to light-dark transition and acclimation to PFD can provide useful information about the photoacclimation of the photosynthetic apparatus, in particular for phytoplankton.

The kinetics and capacity of the xanthophyll cycle can be used as a marker for the photoadaptive state of algal cells and their ecological niches (Dimier et al. 2009). Brunet \& Lavaud (2010) pointed out that there is a need to increase the data set on xanthophyll cycle characteristics such as the light-dependent responses of xanthophyll-cycling pigment, in as many different microalgal species/ groups as possible. There have been many studies on xanthophyll-cycling pigment dynamics in diatoms (e.g., Lavaud et al. 2004) but few studies in other algae. The aim of the present study was to gain additional insight into the relevance of the DD and DT dynamics and photoacclimation in the algal photosynthetic apparatus. The present study investigated the effect of the acclimation PFD on the photoresponse of DD and DT to repetitive light-dark transitions in cultures of Isochrysis galbana (Prymnesiophyceae). Isochrysis galbana has a simple shape (coccoid in fresh cells) and has division patterns typical of phytoplankton
(Chisholm 1981). This species has also been used for studies of photoacclimation (e.g., Falkowski et al. 1985, Fujiki \& Taguchi 2002). Isochrysis galbana had previously been acclimated to four different PFD levels ranging from a limited light condition (LL) to a saturated light condition (SL) under cycles of light and dark, because photoacclimation responses depend on whether the PFD is light-limiting or light-saturating for growth (Raven \& Geider 2003). As the interpretation of the photoacclimation response depends on the method by which phytoplankton mass is expressed (Leonardos 2008), the photoresponses of DD and DT were based on the xanthophyll : Chl $a$ ratio and the cellular pigment content. Because $\mathrm{Chl} a$ is an essential pigment that transfers excitation energy to the reaction center of the photosystem (Scheer 2003), the photoresponses of the DD and/or DT : Chl $a$ ratio can detect changes in the composition and function of the photosystem. The cellular DD and/or DT content also make intuitive sense for photoacclimation since a cell is the smallest population unit (Anning et al. 2000). The examination of xanthophyll-cycling pigment dynamics may provide a better understanding of photoacclimation in the algal photosynthetic apparatus.

\section{Materials and Methods}

Cultures of Isochrysis galbana (Prymnesiophyceae; NEPECC633) were obtained from the North East Pacific Culture Collection (NEPECC) at the University of British Columbia, Canada. The axenic stock cultures were routinely maintained at $25^{\circ} \mathrm{C}$ and at a PFD of $150 \mu \mathrm{mol}$ photons $\mathrm{m}^{-2} \mathrm{sec}^{-1}$ under a $12: 12 \mathrm{~h}$ light : dark cycle in filtered, aged seawater enriched with $\mathrm{f} / 2$ medium (Guillard \& Ryther 1962) using the Eppley culture method (Eppley 1977). Cylindrical 3- or 6-L round-bottom borosilicate glass culture vessels were illuminated from the side. The illumination was provided by cool-white fluorescent tubes (FL30SEX-N, National, Tokyo, Japan) on a 12:12 h lightdark cycle at one of four PFDs: 45, 250, 425, and $1,370 \mu \mathrm{mol}$ photons $\mathrm{m}^{-2} \mathrm{sec}^{-1}$. The spectral PFD of the fluorescence lamp showed six peaks $(406,436,490,545,588$ and $612 \mathrm{~nm}$ ) from 400 to $700 \mathrm{~nm}$. The maximum and minimum of these peaks were observed to be 545 and $406 \mathrm{~nm}$, respectively. The PFD was determined from measurements taken in the center of a similar vessel containing 3 or $6 \mathrm{~L}$ of distilled water using a $4 \pi$-scalar quantum sensor (QSL100, Biospherical Instruments, San Diego, California, USA). The desired light intensities in the culture vessels were obtained by adjusting the number of fluorescent tubes. The cultures were mixed using air supplied through a $0.2-\mu \mathrm{m}$ membrane filter and by a magnetic stirrer at the bottom of the culture vessel. The cultures were operated as continuous cultures for more than three weeks with the dilution rate dictated by the growth rate. The cell concentrations were monitored once per day at hour 6 of the light period. We attempted to maintain a relatively constant cell density at hour 6 of the light period by manually adjusting 
the flow rate of the nutrient medium that was being added to the culture vessels with a peristaltic pump (MP-3A, Eyela, Tokyo, Japan). The steady state was operationally defined in our experiments to be when the cell density at hour 6 of the light period varied by less than $10 \%$ over at least three consecutive sampling times. The growth rate under the steady state was targeted to be $0.3 \mathrm{~d}^{-1}$ under all light conditions. The excess of nitrate was verified by measuring the nitrate concentrations of at least $50 \mu \mathrm{M}$ of the outflow from the culture vessels. The specific growth rate $\mu$ of the culture was calculated using the following equation:

$$
\mu=\left(\ln N_{1}-\ln N_{0}\right) \Delta t^{-1}+D
$$

where $N_{0}$ and $N_{1}$ are the cell densities (cells $\mathrm{mL}^{-1}$ ) at time $t_{0}$ and time $t_{1}$, respectively; $\Delta t$ is the length of the time $\left(\mathrm{d}^{-1}\right)$ interval $\left(t_{1}-t_{0}\right)$; and $D$ is the dilution rate during $\Delta t$. The cultures were acclimated to each light condition for more than three weeks before the start of sampling. All of the incubation experiments were conducted for three lightdark transitions. The samples for the cell and pigment analysis were collected every $3 \mathrm{~h}$ during three light-dark transitions from continuous cultures at a steady state.

\section{Cell density}

The subsamples for measuring cell density were fixed using $5 \%$ formaldehyde and stored in the dark at $4{ }^{\circ} \mathrm{C}$ (Iwasawa et al. 2009). The cell numbers were counted with a hemacytometer (model 35103: Erma, Tokyo, Japan) under a microscope (IMT-2, Olympus, Tokyo, Japan) at 400x magnification.

\section{Pigment analysis}

Triplicate subsamples for pigment analysis were filtered onto Whatman GF/A glass fiber filters (Whatman, Maidstone UK, USA) within 2 min of subsample collection under low vacuum pressure $(<100 \mathrm{~mm} \mathrm{Hg})$ and dark conditions. These filters were immediately frozen and kept in a deep-freezer at $-60^{\circ} \mathrm{C}$ for further analysis. The filters containing cell materials were sonicated for $10 \mathrm{~min}$ in $\mathrm{N}, \mathrm{N}$-dimethylformamide and pigments were extracted at $-20^{\circ} \mathrm{C}$ for $24 \mathrm{~h}$ in the dark (Suzuki \& Ishimaru 1990). The extracts were analyzed on a Beckman HPLC (Model 168 Diode Array Detector, Fullerton, California, USA) with a C-18 reverse-phase column (Ultrasphere 3- $\mu$ m ODS, Beckman, Fullerton, California, USA) using a solvent gradient system as described by Head \& Horne (Head \& Horne 1993). The integrated HPLC peak areas for Chl $a$, DD, and DT were quantified based on standards obtained from the Sigma Chemical Company (Saint Louis, Missouri, USA).

\section{Statistical analysis}

We used model II linear regression analysis. This regression analysis is the most accurate method for estimating the functional relationship between $\mathrm{X}$ and $\mathrm{Y}$ under conditions in which the $\mathrm{X}$ variable is uncontrolled and sub- ject to error (Laws \& Archie 1981). One-way ANOVA was employed to test for a difference in the cellular xanthophyll-cycling pigment content.

\section{Results}

\section{Cell density and pigment response to the light-dark transition}

The cell density and cellular Chl $a$ content exhibited a repetitive photoresponse during the light-dark transitions at each acclimation PFD (Fig. 1). During the light-to-dark transition, the cell density decreased at the end of the first 3 or $6 \mathrm{~h}$ of the dark period due to cell dilution, and subsequently increased in the remaining dark period until the end of the first 3 or $6 \mathrm{~h}$ of the light period, due to cell division prevailing against cell dilution, for all PFD conditions except for the lowest acclimation PFD. Under the lowest acclimation PFD, the cell density was relatively constant throughout the light-dark transition. When the cell densities were low, the cellular Chl $a$ levels were high and vice versa (Fig. 1). The cellular Chl $a$ level began to increase during the first $9 \mathrm{~h}$ or by the end of the light period, due to pigment synthesis. The Chl $a$ level began to decrease toward the end of the dark period, due to cell division, and later increased again at the dark-to-light transition for all
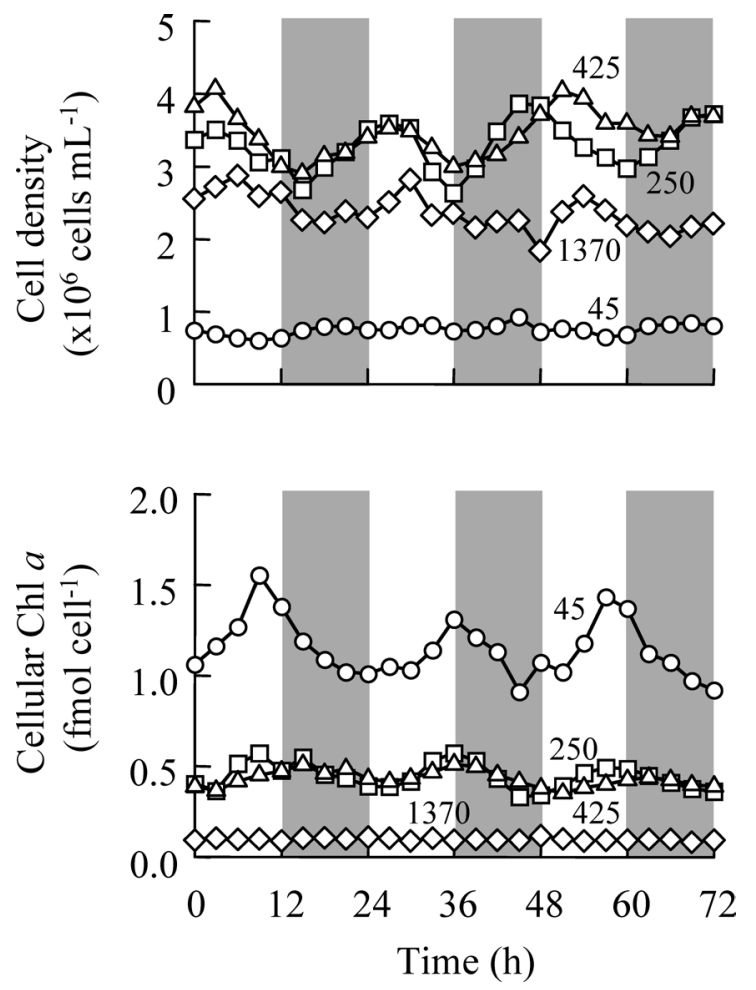

Fig. 1. Cell density (upper) and cellular Chl $a$ content (lower) under light-dark transition. Acclimation PFD levels: 45 (circles), 250 (squares), 425 (triangles), and 1370 (diamonds) $\mu \mathrm{mol}$ photons $\mathrm{m}^{-2} \mathrm{sec}^{-1}$. Grey boxes indicate dark phase. 

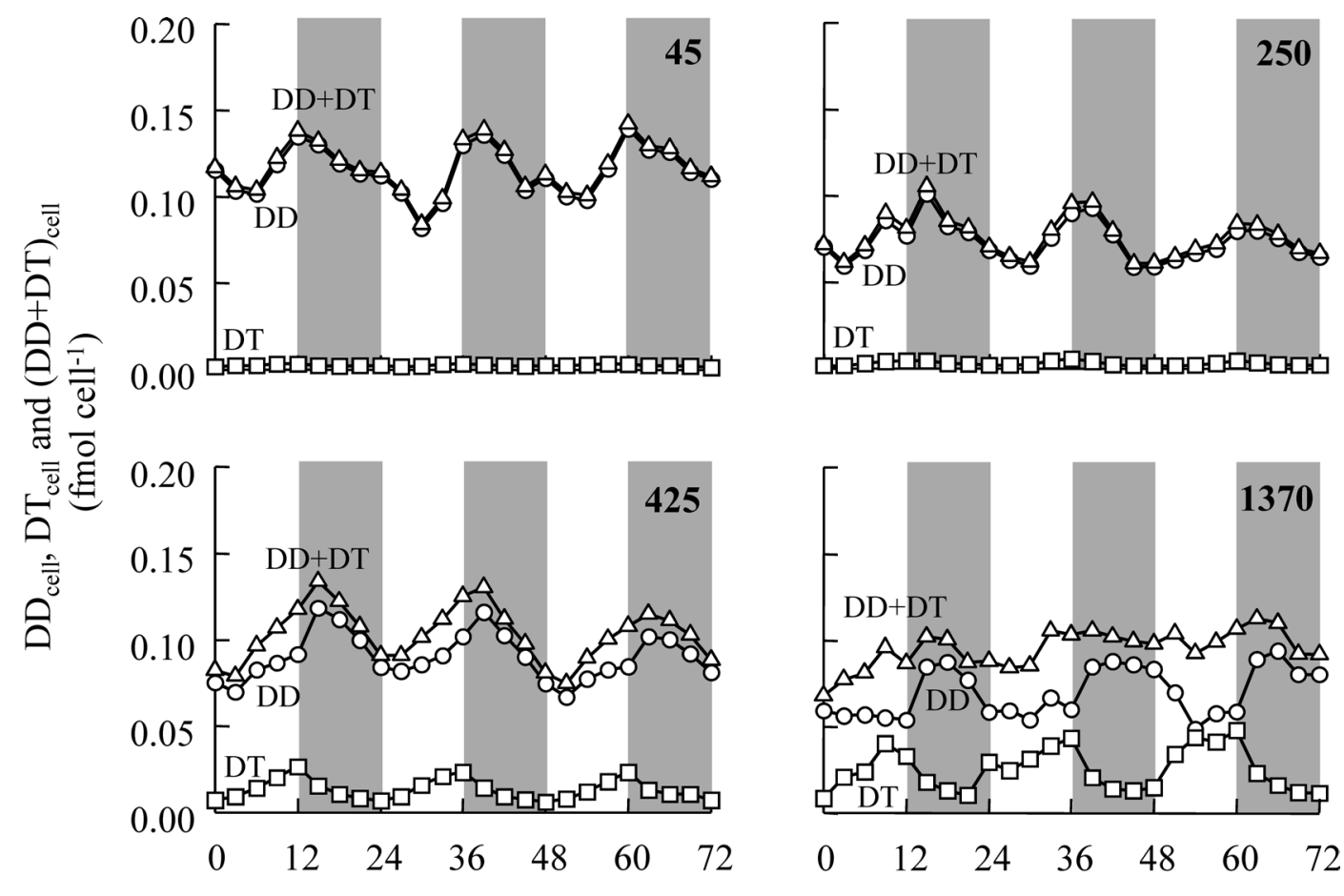

Time (h)

Fig. 2. Photoresponses of the cellular content of xanthophyll pigments to light-dark transition at 45, 250, 425 and $1,370 \mu \mathrm{mol}$ photons $\mathrm{m}^{-2} \mathrm{sec}^{-1}$. Open symbols of circles, squares and triangles indicate $\mathrm{DD}_{\text {cell }}, \mathrm{DT}_{\text {cell }}$ and $(\mathrm{DD}+\mathrm{DT})_{\text {cell }}$, respectively. Grey boxes indicate dark phase.

PFD conditions except for in the highest acclimation PFD. Under the highest acclimation PFD almost no response was observed with regards to the cellular Chl $a$ content.

The photoresponses of xanthophyll pigments to lightdark transitions differed between the acclimation PFDs. Under the two lower acclimation PFDs, the pool of cellular xanthophyll pigments $\left[(\mathrm{DD}+\mathrm{DT})_{\text {cell }}\right]$ and the cellular DD content $\left(\mathrm{DD}_{\text {cell }}\right)$ continued to decrease during the first half of the light period and subsequently began to increase from the middle of the light period to the end of the light period or through the first $3 \mathrm{~h}$ of the dark period (Fig. 2). In contrast to the $(\mathrm{DD}+\mathrm{DT})_{\text {cell }}$ and $\mathrm{DD}_{\text {cell }}$ levels, the cellular DT levels $\left(\mathrm{DT}_{\text {cell }}\right)$ under the two lower acclimation PFDs were relatively constant under the light-dark transition. Under $425 \mu$ mol photons $\mathrm{m}^{-2} \mathrm{sec}^{-1}$, the $(\mathrm{DD}+\mathrm{DT})_{\text {cell }}$ and the $\mathrm{DD}_{\text {cell }}$ continued to increase during the light period and through the first $3 \mathrm{~h}$ of the dark period and later decreased at the end of the dark period. The $\mathrm{DT}_{\text {cell }}$ increased during the light period and decreased during the dark period. Under the highest acclimation PFD, the (DD+DT) cell continued to increase during the light period and through the middle of the dark period and subsequently decreased at the end of the dark period. In contrast to the $(\mathrm{DD}+\mathrm{DT})_{\text {cell }}$, the $\mathrm{DD}_{\text {cell }}$ was relatively constant during the light period and increased during the first $3 \mathrm{~h}$ of the dark period; it began to decrease thereafter from the middle of the dark period to the end of the dark period. The $\mathrm{DT}_{\text {cell }}$ increased during the light period and decreased during the dark period.

The photoresponses of the DD and/or DT : Chl $a$ ratios $\left([\mathrm{DD}+\mathrm{DT}]_{\mathrm{Chl} a}, \mathrm{DD}_{\mathrm{Chl} a}, \mathrm{DT}_{\mathrm{Chl} a}\right)$ were similar to the cellular xanthophyll pigment responses at each acclimation PFD (Fig. 3). Stoichiometric variations were observed between the $\mathrm{DD}_{\mathrm{Chl} a}$ and $\mathrm{DT}_{\mathrm{Chl} a}$ during the first $3 \mathrm{~h}$ of the light to dark or dark to light transitions at the two higher acclimation PFDs. The magnitude of the stoichiometric variations under $1,370 \mu \mathrm{mol}$ photons $\mathrm{m}^{-2} \mathrm{sec}^{-1}$ was 10 times as large as that under $425 \mu \mathrm{mol}$ photons $\mathrm{m}^{-2} \mathrm{sec}^{-1}$.

\section{Relationship between DD or DT and DD+DT}

Linear relationships between DD or DT and DD+DT were obtained at all four experimental PFDs, whether the data were normalized to the cell density (Table 1) or to Chl $a$ concentration (Table 2) during both light and dark periods (Fig. 4). A highly significant relationship $(p<0.001)$ was observed between $\mathrm{DD}_{\text {cell }}$ and (DD+DT) $)_{\text {cell }}$ for all PFD conditions, except for in the light phase at the highest acclimation PFD (Table 1). At the two lower acclimation PFDs, the slopes for these relationships were approximately $>0.9$ during both the light and dark phases. During the light phase, the slopes ranged from approximate unity at the lowest acclimation PFD to 0.3 at the highest acclimation PFD. The slopes obtained during the dark phase were less variable than the slopes obtained during the light 


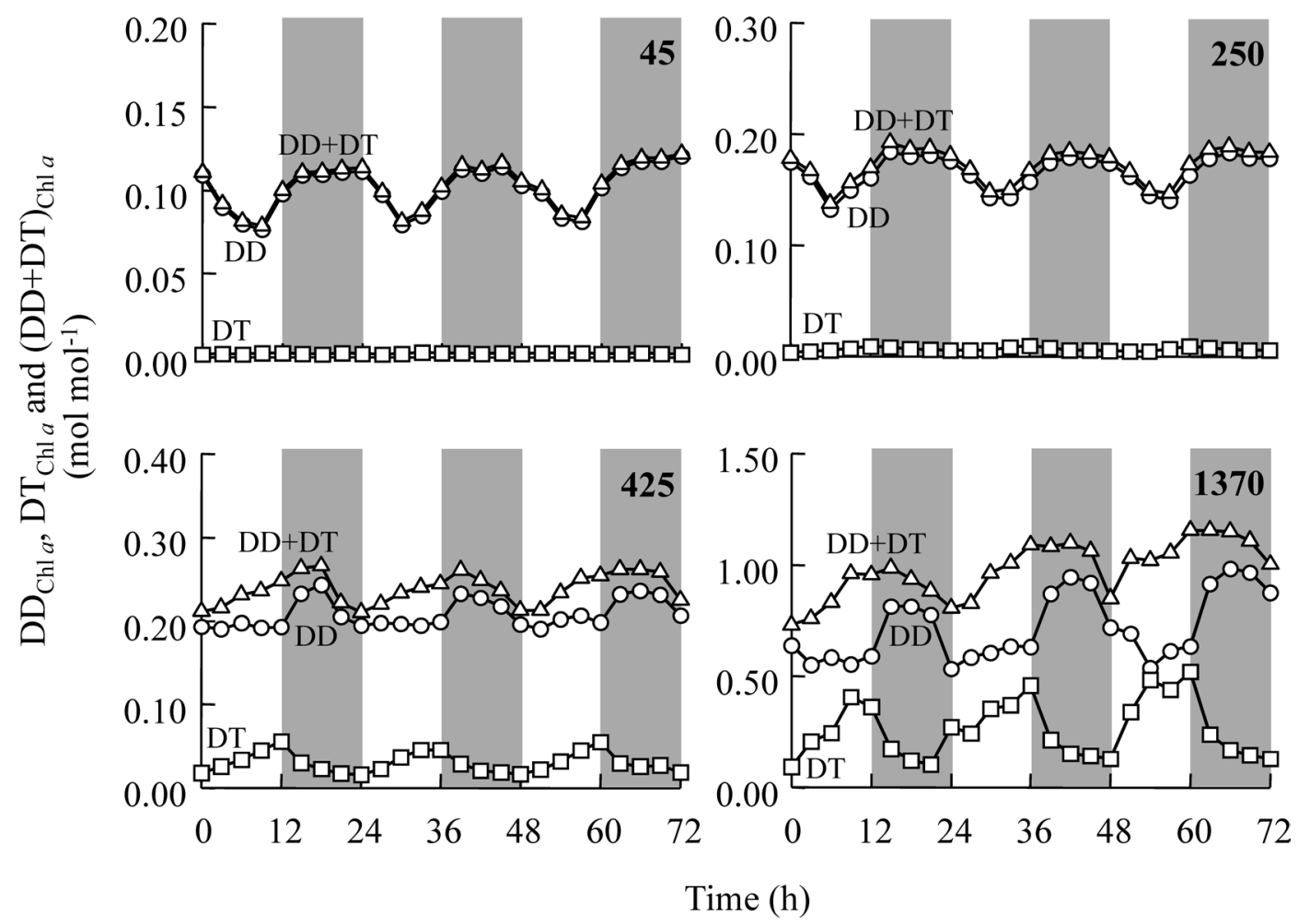

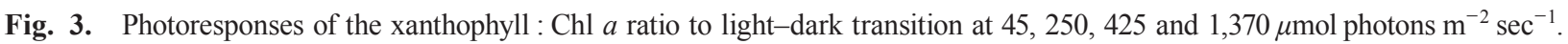
Open symbols of circles, squares and triangles indicate $\mathrm{DD}_{\mathrm{Chl} a}, \mathrm{DT}_{\mathrm{Chl} a}$ and $(\mathrm{DD}+\mathrm{DT})_{\mathrm{Chl} a}$, respectively. Grey boxes indicate dark phase.

Table 1. Linear regression analyses of the relationships between DD or DT and (DD+DT) on a cell basis.

\begin{tabular}{|c|c|c|c|c|c|c|c|c|}
\hline \multirow{2}{*}{ PFD } & \multicolumn{4}{|c|}{ Light } & \multicolumn{4}{|c|}{ Dark } \\
\hline & Slope & Intercept & $\mathrm{n}$ & $r^{2}$ & Slope & Intercept & $\mathrm{n}$ & $r^{2}$ \\
\hline \multicolumn{9}{|l|}{ DD } \\
\hline 45 & 0.978 & -0.0003 & 12 & 0.99 & 0.969 & 0.0015 & 13 & 0.99 \\
\hline 250 & 0.892 & 0.0048 & 12 & 0.99 & 0.932 & 0.0026 & 13 & 0.99 \\
\hline 425 & 0.608 & 0.0226 & 12 & 0.94 & 0.843 & 0.0068 & 13 & 0.99 \\
\hline 1370 & 0.298 & 0.0303 & 12 & $0.28^{\mathrm{ns}}$ & 0.705 & 0.0140 & 12 & 0.92 \\
\hline \multicolumn{9}{|l|}{ DT } \\
\hline 45 & 0.022 & 0.0003 & 12 & 0.52 & 0.031 & -0.0015 & 13 & 0.33 \\
\hline 250 & 0.113 & -0.0051 & 12 & 0.90 & 0.065 & -0.0024 & 13 & 0.88 \\
\hline 425 & 0.393 & -0.0227 & 12 & 0.88 & 0.158 & -0.0069 & 13 & 0.83 \\
\hline 1370 & 0.710 & -0.0309 & 12 & 0.70 & 0.301 & -0.0146 & 12 & 0.68 \\
\hline
\end{tabular}

ns indicates no significance $(p>0.05)$.

phase. Significant relationships were also observed between the $\mathrm{DT}_{\text {cell }}$ and $(\mathrm{DD}+\mathrm{DT})_{\text {cell }}$ during both the light and dark periods at all PFD levels $(p<0.05)$ (Table 1). These slopes increased with increasing acclimation PFD from $0.02-0.03$ at the lowest acclimation PFD to 0.7 during the light phase and 0.3 during the dark phase at the highest acclimation PFD. Except for the light period at the lowest acclimation PFD, the $X$-axis intercept $(\mathrm{DT}=0)$ of all of the lines converged around $0.049 \pm 0.008$ (mean \pm one standard deviation) fmol (DD+DT) cell ${ }^{-1}$ during the light period and $0.044 \pm 0.005 \mathrm{fmol}(\mathrm{DD}+\mathrm{DT})$ cell $^{-1}$ during the dark period (Fig. 4).

Relationships similar to those observed for the cell density-specific values were also obtained for the xanthophyll : Chl $a$ ratio during both the light and dark periods (Table 2). The slopes for the relationships between $\mathrm{DD}_{\mathrm{Chl} a}$ and (DD+DT) $)_{\mathrm{Chl} a}$ were 1.0 or close to 1.0 during both the light and dark periods at the lowest acclimation PFD and 
Table 2. Linear regression analyses of the relationships between DD or DT and (DD+DT) on a Chl $a$ basis.

\begin{tabular}{|c|c|c|c|c|c|c|c|c|}
\hline \multirow{2}{*}{ PFD } & \multicolumn{4}{|c|}{ Light } & \multicolumn{4}{|c|}{ Dark } \\
\hline & Slope & Intercept & $\mathrm{n}$ & $r^{2}$ & Slope & Intercept & $\mathrm{n}$ & $r^{2}$ \\
\hline \multicolumn{9}{|l|}{ DD } \\
\hline 45 & 1.00 & -0.0019 & 12 & 0.99 & 0.989 & -0.0008 & 13 & 0.99 \\
\hline 250 & 0.931 & 0.0041 & 12 & 0.97 & 0.821 & 0.0269 & 13 & 0.93 \\
\hline 425 & 0.189 & 0.152 & 12 & $0.27^{\mathrm{ns}}$ & 0.784 & 0.0299 & 13 & 0.98 \\
\hline 1370 & 0.201 & 0.407 & 12 & $0.28^{\mathrm{ns}}$ & 0.758 & 0.0917 & 12 & 0.93 \\
\hline \multicolumn{9}{|l|}{ DT } \\
\hline 45 & 0.004 & 0.0019 & 12 & $0.02^{\mathrm{ns}}$ & 0.002 & 0.0019 & 13 & $0.00^{\mathrm{ns}}$ \\
\hline 250 & 0.068 & -0.0040 & 12 & $0.14^{\mathrm{ns}}$ & 0.179 & -0.0268 & 13 & 0.46 \\
\hline 425 & 0.811 & -0.152 & 12 & 0.87 & 0.216 & -0.0298 & 13 & 0.80 \\
\hline 1370 & 0.799 & -0.407 & 12 & 0.86 & 0.242 & -0.0917 & 12 & 0.56 \\
\hline
\end{tabular}

ns indicates no significance $(p>0.05)$.

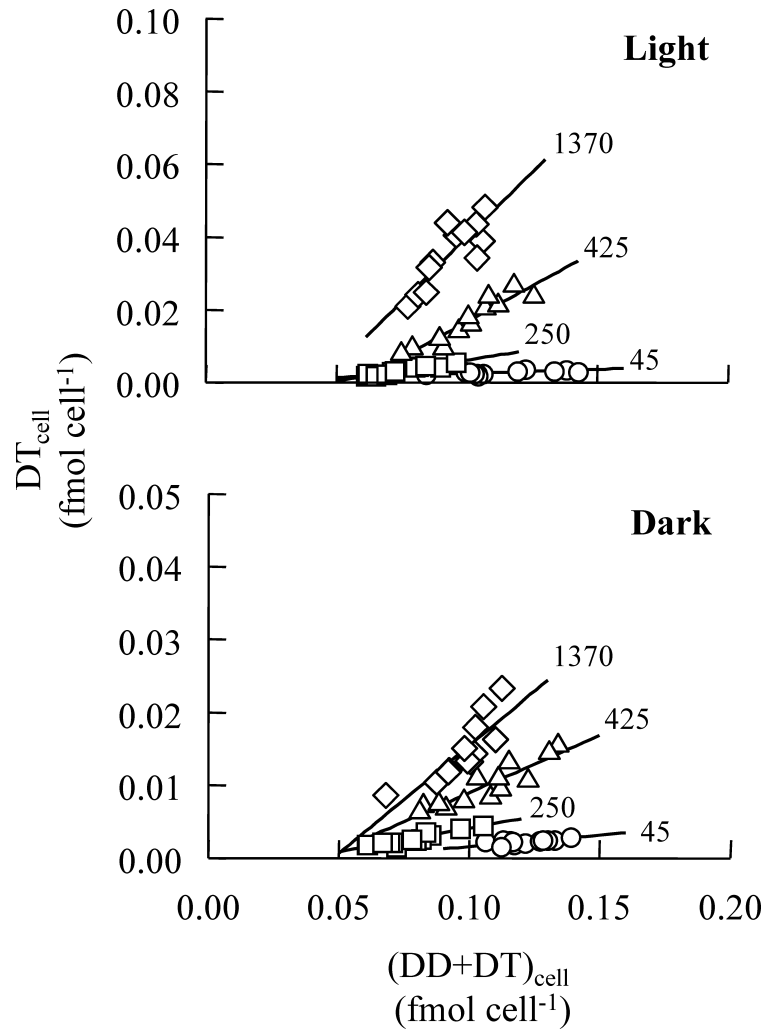

Fig. 4. Relationship between cellular DT content and cellular $(\mathrm{DD}+\mathrm{DT})$ content in light and dark phases. Acclimation PFD levels: 45 (circles), 250 (squares), 425 (triangles), and 1370 (diamonds) $\mu \mathrm{mol}$ photons $\mathrm{m}^{-2} \mathrm{sec}^{-1}$.

decreased to 0.20 during the light period and 0.76 during the dark period. The slopes for the relationships between $\mathrm{DT}_{\mathrm{Chl} a}$ and $(\mathrm{DD}+\mathrm{DT})_{\mathrm{Chl} a}$ were the lowest $(<0.004)$ at low PFDs and generally increased to 0.80 with increasing acclimation PFD during the light period and to 0.24 during the dark period.

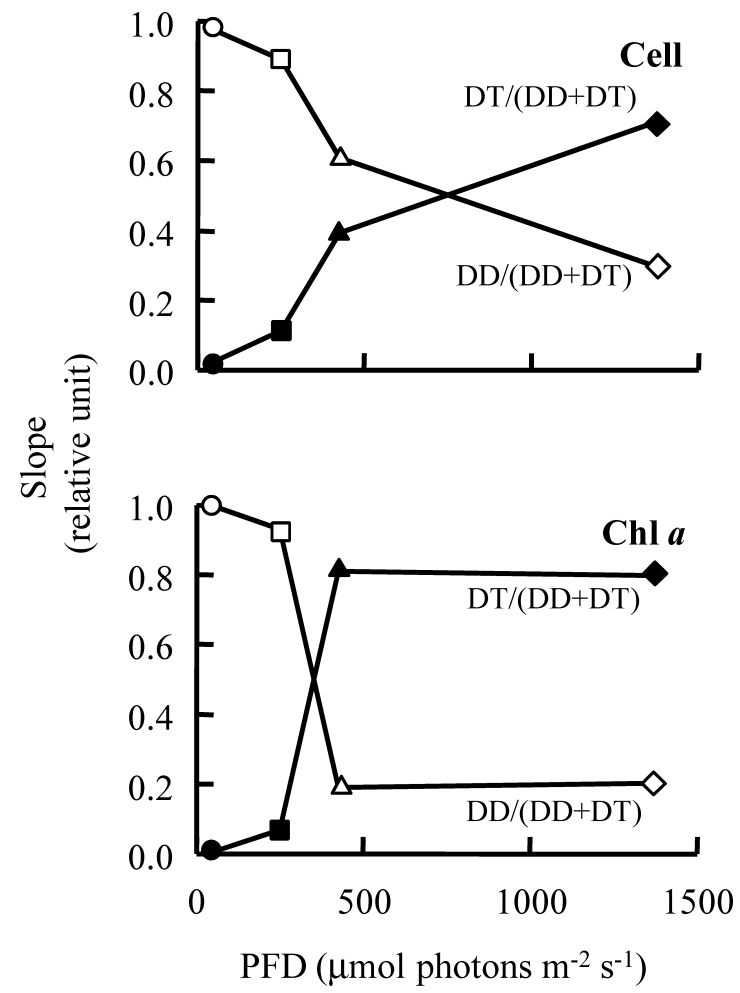

Fig. 5. Changes in the slopes of the relationships between DD and (DD+DT) (open symbols) and the relationships between DT and (DD + DT) (closed symbols) to PFD during the light phase on the basis of the cellular pigment content (upper) and the xanthophyll : Chl $a$ ratio (lower). Acclimation PFD levels: 45 (circles), 250 (squares), 425 (triangles), and 1370 (diamonds) $\mu \mathrm{mol}$ photons $\mathrm{m}^{-2} \mathrm{sec}^{-1}$.

\section{Discussion}

The patterns of the photoresponse according to cell density and cellular Chl $a$ content under light-dark cycles obtained in this study are similar to those found in previous 
studies (e.g., Post et al. 1984, DuRand et al. 2002, Harris et al. 2009). The photoresponses, measured by cell density and cellular Chl a content in Isochrysis galbana during the light-dark transition, were consistent with the concept that cell division during the dark phase is common among phytoplankton (Chisholm 1981, Jacquet et al. 2001) and that cellular Chl $a$ content increases with pigment synthesis during the light phase and decreases during the dark phase upon cell division (Kohata \& Watanabe 1988, Ragni \& D'alcala 2007). Photoacclimation is commonly demonstrated as a reduction in the cellular Chl $a$ content in response to increased PFD (e.g., MacIntyre et al. 2002). The decline in the level of cellular Chl $a$ content with increasing acclimation PFD that was observed in the present study may represent evidence of success in acclimation to each growth PFD.

Repetitive photoresponses of cellular xanthophyll pigment content and xanthophyll pigment : Chl $a$ ratio under light-dark cycles have been reported in the diatom Pheaodactylum tricornutum (Ragni \& D'alcala 2007). For I. galbana, the cellular xanthophyll pigment content and the xanthophyll pigment : $\mathrm{Chl} a$ ratio exhibited a repetitive response to the light-dark transition. It was clear that acclimation PFD affected the xanthophyll pigment: Chl $a$ ratio of I. galbana. In general, xanthophyll pigment : Chl $a$ ratio increases with the growth PFD due to both an increase in cellular xanthophyll pigment content and a decrease in the cellular Chl $a$ content with an increased growth PFD (MacIntyre et al. 2002). However, the level of the cellular xanthophyll pigment content of I. galbana changed slightly compared with the decrease of cellular Chl $a$ content over the range of acclimation PFDs. This finding suggests that the increase in the level of xanthophyll pigment : Chl $a$ ratio of $I$. galbana with acclimation PFD results from the simultaneous decline in the level of cellular Chl $a$ content in response to increasing acclimation PFD. Because the decline in the level of cellular Chl $a$ content lowers the excess of energy reaching the photosystems, these mechanisms can be photoprotective and/or photoacclimatory (Harris et. 2009). In I. galbana, the xanthophyll pigment: $\mathrm{Chl} a$ ratio depends on cellular Chl $a$ content.

The patterns of the photoresponses of the cellular xanthophyll pigment content and the xanthophyll pigment : Chl $a$ ratio in I. galbana under light-dark transition depended on the acclimation PFD. The dependence in the patterns of these photoresponses to the acclimation PFD indicates an effect of the acclimation PFD on these pigment dynamics during light-dark transitions. Dynamics of DD and DT during light-dark transition are controlled by three processes (Olaizola et al. 1994, Lavaud et al. 2004, Harris et al. 2009, Polimene et al. 2012). The first process is de novo synthesis or the degradation of $\mathrm{DD}$ and $\mathrm{DT}$ (Olaizola et al. 1994, Förster et al. 2009, Harris et al. 2009, Polimene et al. 2012). The de novo process represents a fundamental process controlling the xanthophyll pigment dynamics during light-dark transitions, regardless of the acclimation PFD. The occurrence of the de novo process as related to xanthophyll pigments is demonstrated by the changes in the pool size of the xanthophyll pigments $\left([\mathrm{DD}+\mathrm{DT}]_{\mathrm{Chl} a}\right)($ Olaizola \& Yamamoto 1994, Mewes \& Richter 2002, Lavaud et al. 2004). The second process is the light-dependent interconversion between DD and Fuco (Harris et al. 2009, Polimene et al. 2012). The interconversion also leads to changes in the $\mathrm{DD}_{\mathrm{Chl} a}$ and $(\mathrm{DD}+\mathrm{DT})_{\mathrm{Chl} a}$. The third process is the xanthophyll cycling process, which is the reversible conversion between DD and DT (Hager \& Stransky 1970). The xanthophyll cycling process results in a stoichiometric increase in $\mathrm{DT}_{\mathrm{Chl} a}$ and decrease in $\mathrm{DD}_{\mathrm{Chl} a}$ during high PFD exposure and vice versa during low PFD exposure or during the dark phase. Therefore, $(\mathrm{DD}+\mathrm{DT})_{\mathrm{Chl} a}$ remains constant in the xanthophyll cycling process when the de novo process and interconversion between DD and Fuco are excluded. The dependence of the xanthophyll cycling process on the PFD acclimation (Hager 1980, Yamamoto 1985) suggests that the effect of the xanthophyll cycling process on the DD and DT dynamics during lightdark transitions varies with the PFD. Because the rate and degree of de-epoxidation are greater at higher PFDs (Lavaud et al. 2004), the effect of the xanthophyll cycling process on xanthophyll pigment dynamics during lightdark transitions may become larger at higher PFDs. No stoichiometric changes were observed between $\mathrm{DD}_{\mathrm{Chl} a}$ and $\mathrm{DT}_{\mathrm{Chl} a}$ at 45 or $250 \mu \mathrm{mol}$ photons $\mathrm{m}^{-2} \mathrm{sec}^{-1}$, suggesting that these pigment dynamics might be controlled by the de novo process and interconverstion between DD and Fuco, rather than the xanthophyll cycling process. In contrast, the xanthophyll pigment dynamics at the two higher acclimation PFDs might be controlled by all three processes. The occurrence of the de novo process and interconversion between DD and Fuco for these pigments was demonstrated by the change in (DD+DT) $)_{\mathrm{Chl} a}$ in the light and dark phases and the decrease in $\mathrm{DD}_{\mathrm{Chl} a}$ during the last $6 \mathrm{~h}$ of the dark phase under 425 and $1,370 \mu$ mol photons $\mathrm{m}^{-2} \mathrm{sec}^{-1}$. Additionally, the occurrence of the xanthophyll cycling process was shown by stoichiometric variations between $\mathrm{DD}_{\mathrm{Chl} a}$ and $\mathrm{DT}_{\mathrm{Chl} a}$ during the first $3 \mathrm{~h}$ of the light to dark or dark to light transitions at 425 and $1,370 \mu \mathrm{mol}$ photons $\mathrm{m}^{-2} \mathrm{sec}^{-1}$. Furthermore, the large stoichiometric variations between $\mathrm{DD}_{\mathrm{Chl} a}$ and $\mathrm{DT}_{\mathrm{Chl} a}$ at the higher acclimation PFDs suggest that the role of the xanthophyll cycling process in xanthophyll pigment dynamics is significant at high acclimation PFDs. This idea is consistent with the concept that phytoplankton activate the xanthophyll cycle reaction at high PFDs as an important process related to the photoprotection of the PSII (Müller et al. 2001). The dependence of xanthophyll pigment dynamics on the acclimation PFD suggests that it is associated with both de novo and xanthophyll cycling processes.

The existence of the $X$-axis intercept in the relationship between the $\mathrm{DT}_{\text {cell }}$ and $(\mathrm{DD}+\mathrm{DT})_{\text {cell }}$ under all acclimation PFDs (Fig. 4) suggests the persistent existence of a fraction 
of the DD that may not be directly associated with DT synthesis. Because DT is converted from DD through de-epoxidation, this fraction may be non-convertible, regardless of the acclimation PFD. The non-convertible fraction of DD was estimated to be approximately $0.046 \mathrm{fmol}$ DD $\mathrm{cell}^{-1}$ for I. galbana in the present study. This non-convertible fraction could be a constitutive portion of the lightharvesting complex (LHC) as suggested by Lohr \& Wilhelm (2001). According to Lohr \& Wilhelm (2001), the percentage of the constitutive DD within the LHC $\left(\mathrm{DD}_{\mathrm{LHC}}\right)$ was estimated to be $6 \%$ of the total carotenoids, corresponding to $37 \%$ of $\mathrm{DD}+\mathrm{DT}$ for the diatom P. tricornutum at steady-state growth in low light conditions $(40 \mu \mathrm{mol}$ photons $\mathrm{m}^{-2} \mathrm{sec}^{-1}$ ). If the non-convertible fraction of the DD estimated in the present study is assumed to be the $\mathrm{DD}_{\mathrm{LHC}}$, then a similar percentage $(39 \%)$ of $\mathrm{DD}+\mathrm{DT}$ is obtained for I. galbana grown at the lowest acclimation PFD ( $45 \mu \mathrm{mol}$ photons $\mathrm{m}^{-2} \mathrm{sec}^{-1}$ ). A percentage similar to that found in diatoms may be explained by the coincident fact that prymnesiophytes and diatoms have a similar LHC that contains fucoxanthin-chlorophyll a/c-protein (Fawley et al. 1987, Macpherson \& Hiller 2003). The de-epoxidation state (DES), defined conventionally as the ratio of the DT to DD+DT concentrations (e.g., Janknegt et al. 2008), could potentially be underestimated, due to the presence of the non-convertible fraction of the DD (Lavaud et al. 2004). Estimating the DES considering only the convertible fraction of the DD enabled us to assess the functional de-epoxidation state accurately.

The slopes of the relationship between the DD or DT and DD+DT on either a cell or chlorophyll basis indicate a quantitative index of the extent of DD and DT dynamics. The change in the slopes of the relationship between the $\mathrm{DD}$ or DT and DD+DT in response to the variation of acclimation PFD suggests that DD and DT dynamics vary with the acclimation PFD. The change in the slope of the relationship between the DD or DT and DD+DT of I. galbana during the light phases in response to the variation of acclimation PFD was characterized by either a linear or sigmoidal function, respectively (Fig. 5, Obata 2010). The different functions arise from the different physiological bases of the estimation, i.e., measurements coming from either a whole cell or the $\mathrm{Chl} a$ mass. Examining the photoacclimation parameters at a cellular level makes intuitive sense (Anning et al. 2000). The linear change in the cellspecific slopes in response to the variation of the acclimation PFD (Fig. 5) suggests that the DD and DT dynamics during the light-dark transition can be directly determined by the acclimation PFD. Alternatively, the sigmoid change in the Chl $a$-specific slopes in response to the variation of the acclimation PFD may be determined by the light conditions. Based on the relationship between the algal growth rate and the acclimated PFD (MacIntyre et al. 2002), light conditions for algal growth can be categorized into two types: limited light conditions (LL), where the growth rate depends on the PFD, or saturated light conditions (SL), where the growth rate is at its maximum. For I. galbana, there may be a range of LL conditions corresponding to PFDs below approximately $200-300 \mu$ mol photons $\mathrm{m}^{-2} \mathrm{sec}^{-1}$ and a range of SL conditions at higher PFDs, because their growth rate becomes saturated at around approximately 200-300 $\mu \mathrm{mol}$ photons $\mathrm{m}^{-2} \mathrm{sec}^{-1}$ (Jokiel \& York 1984, Falkowski et al. 1985). Examining the photoacclimation parameters on the basis of $\mathrm{Chl} a$ provides insight into the antenna of the photosystem because Chl $a$ transfers excitation energy to the reaction center of the photosystem (Scheer 2003). The high slopes based on the $\mathrm{DD}_{\mathrm{Chl} a}$ and low slopes based on the $\mathrm{DT}_{\mathrm{Chl} a}$ under the LL conditions suggests that algae may have enhanced light harvesting under LL conditions. The opposite situation, i.e., low slopes based on $\mathrm{DD}_{\mathrm{Chl} a}$ and high slopes based on $\mathrm{DT}_{\mathrm{Chl} a}$, under the SL conditions suggests that algae may have enhanced photoprotective energy dissipation. The suggestions obtained from examining the two slopes based on $\mathrm{DD}_{\mathrm{Chl} a}$ and $\mathrm{DT}_{\mathrm{Chl} a}$ to the light conditions of LL vs. SL in the present study agree with the findings of previous studies (e.g., Stolte et al. 2000) that demonstrated the consequences of photoacclimation through the relative abundances of photosynthetic and photoprotective pigments.

In addition, the position of the intersection between the sigmoid changes in Chl $a$-specific slopes in response to the variation of the acclimation PFD in the present study is close to the "hinge point" that was observed for the photoacclimation of microalgae with respect to the relative abundance of photosynthetic and photoprotective pigments (MacIntyre et al. 2002). The slopes of the relationship between DD or DT and DD+DT on a Chl $a$ basis during the light-dark transition may be useful as an index of the relevant roles of these xanthophyll-cycling pigments in light harvesting or photoprotection and as a marker of the physiological status of phytoplankton with respect to PFD. An examination of the slope may provide information for a better understanding of photoacclimation in the photosynthetic apparatus of algae.

\section{Acknowledgements}

Technical assistance was provided by A. Mizobuchi, Y. Ishiwata, N. Ohi, M. Maeda, T. Gorai and T. Katayama. This research was partially funded by a grant-in-aid from the Ministry of Education and Science \#16580161. The two anonymous referees are kindly acknowledged for their comments and criticisms on an earlier version of the manuscript.

\section{References}

Anning T, MacIntyre HL, Pratt SM, Sammes PJ, Gibb S, Geider RJ (2000) Photoacclimation in the marine diatom Skeletonema costatum. Limnol Oceanogr 45: 1807-1817.

Brunet C, Lavaud J (2010) Can the xanthophyll cycle help extract the essence of the microalgal functional response to a variable 
light environment? J Plankton Res 32: 1609-1617.

Chisholm SW (1981) Temporal patterns of cell division in unicellular algae. Can Bull Fish Aquat Sci 210: 150-181.

Cullen JJ (1990) On models of growth and photosynthesis in phytoplankton. Deep-Sea Res 37: 667-683.

Cullen JJ, Lewis MR (1988) The kinetics of algal photoadaptation in the context of vertical mixing. J Plankton Res 10: 10391063.

Dimier C, Giovanni S, Ferdinando T, Burnet C (2009) Comparative ecophysiology of the xanthophyll cycle in six marine phytoplankton species. Protist 160: 397-411.

DuRand MD, Green RE, Sosik HM, Olson RJ (2002) Diel variations in optical properties of Micromonas pusilla (Prasinophyceae). J Phycol 38: 1132-1142.

Eonseon J, Polle JEW, Kumlee H, Hyun SM and Chang M (2003) Xanthophylls in microalgae: from biosynthesis to biotechnological mass production and application. J Micro Biotec 13: 165-174.

Eppley RW (1977) The growth and culture of diatoms. In: The Biology of Diatoms, Botanical Monographs Vol. 13 (ed Werner D). University of California Press, Berkeley and Los Angeles, pp. 24-64.

Falkowski PG (1984) Physiological responses of phytoplankton to natural light regimes. J Plankton Res 6: 295-307.

Falkowski PG, Dubinsky Z (1980) Light-shade adaptation of Stylophora pistillata, a hermatypic coral from the Gulf of Eilat. Nature 289: 172-174.

Falkowski PG, La Roche J (1991) Molecular biology in studies of ocean processes. Int Rev Cytology 128: 261-303.

Falkowski PG, Dubinsky Z, Wyman K (1985) Growth-irradiance relationships in phytoplankton. Limnol Oceanogr 30: 311-321.

Fawley MW, Morton SJ, Stewart KD, Mattox KR (1987) Evidence for a common evolutionary origin of light-harvesting fucoxanthin chlorophyll a/c-protein complexes of Pavlova gyrans (Prymnesiophyceae) and Phaeodactirum tricornutum (Bacillariophyceae). J Phycol 23: 377-381.

Förster B, Osmond CB, Pogson BJ (2009) De novo synthesis and degradation of Lx and V cycle pigments during shade and sun acclimation in avocado leaves. Plant Physiol 149: 1179-1195.

Fujiki T, Taguchi S (2002) Variability in chlorophyll $a$ specific absorption coefficient in marine phytoplankton as a function of cell size and irradiance. J Plankton Res 24: 859-874.

Goss R, Jakob T (2010) Regulation and function of xanthophyll cycle-dependent photoprotection in algae. Photosynth Res 106: 103-122.

Guillard RRL, Ryther JH (1962) Studies of marine planktonic diatoms I. Cyclotella nana Hustedt and Detonula confervacea Cleve. Can J Microbiol 8: 229-239.

Hager A (1980) The reversible, light-induced conversions of xanthophylls in the chloroplast. In: Pigments in Plants (ed Czygen FC). Fisher, Stuttgart, pp. 57-79.

Hager A, Stransky H (1970) The carotenoid pattern and occurrence of the light induced xanthophyll cycle in various classes of algae V: a few members of the Cryptophyceae, Euglenophyceae, Bacillariophyceae, Chrysophyceae and Phaeophyceae. Arch Mikobiol 73: 77-89.

Harris GN, Scanlan Dj, Geider RJ (2009) Responses of Emiliania huxleyi (Prymnesiophyceae) to step changes in photon flux density. Eur J Phycol 44: 31-48.

Harrison WG, Platt T (1986) Photosynthesis-irradiance relationships in polar and temperate phytoplankton populations. Polar Biol 5: 153-164.

Head EJH, Horne EPW (1993) Pigment transformation and vertical flux in an area of convergence in the North Atlantic. DeepSea Res II 40: 329-346.

Iwasawa K, Murata A, Taguchi S (2009) Cell shrinkage of Isochrysis galbana (Prymnesiophyceae) during storage with preservatives. Plankt Benthos Res 4: 120-121.

Jacquet S, Partensky F, Lennon J, Vaulot D (2001) Diel patterns of growth and division in marine picoplantkon in culture. J Phycol 37: 357-369.

Janknegt PJ, van de Poll WH, Visser RJW, Rijstenbil JW, Buma AGJ (2008) Oxidative stress responses in the marine Antarctic diatom Chaetceros brevis (Bacillariophyceae) during photoacclimation. J Phycol 44: 957-966.

Jerlov NG (1976) Marine Optics. Academic Press, London, 231 pp.

Jokiel PL, York RH Jr (1984) Importance of ultraviolet radiation in photoinhibition of microalgal growth. Limnol Oceanogr 29: 192-199.

Kohata K, Watanabe M (1988) Diel changes in the composition of photosynthetic pigments and cellular carbon and nitrogen in Chattonella antique (Raphidophyceae). J Phycol 24: 58-66.

Lavaud J, Rousseau B, Etienne A-L (2004) General features of photoprotection by energy dissipation in planktonic diatoms (Bacillariophyceae). J Phycol 40: 130-137.

Laws EA, Archie JW (1981) Appropriate use of regression analysis in marine biology. Mar Biol 65: 13-16.

Leonardos N (2008) Physiological steady state of phytoplankton in the field? An example based on pigment profile of Emiliania huxleyi (Haptophyta) during a light shift. Limnol Oceanogr 53: 306-311.

Lohr M, Wilhelm C (1999) Algae displaying the diadinoxanthin cycle also possess the violaxanthin cycle. Proc Natl Acad Sci USA 96: 8784-8789.

Lohr M, Wilhelm C (2001) Xanthophyll synthesis in diatoms: quantification of putative intermediates and comparison of pigment conversion kinetics with rate constants derived from a model. Planta 212: 382-391.

MacIntyre HL, Kana TM, Anning T, Geider RJ (2002) Photoacclimation of photosynthesis irradiance response curve and photosynthetic pigments in microalgae and cyanobacteria. J Phycol 38: 17-38.

Macpherson AN, Hiller RG (2003) Light-harvesting systems in chlorophyll $c$-containing algae. In: Light-Harvesting Antennae in Photosynthesis (eds Green R, Parsons WW). Kluwer Academic Publishers, Netherlands, pp. 323-352.

Mewes H, Richter M (2002) Supplementary ultraviolet-B radiation induces a rapid reversal of the diadinoxanthin cycle in the strong light-exposed diatom Phaeodactylum tricornutum. Plant Physiol 130: 1527-1535.

Müller P, Li X, Niyogi KK (2001) Non-photochemical quenching. A response to excess light energy. Plant Physiol 125: $1558-1566$.

Obata M (2010) Photoacclimation strategy in photosystem II of Prymnesiophyceae Isochrysis galbana. Available at: http:// 
www.t.soka.ac.jp/assets/pdf/grad/cou_dc/bio/obata.pdf (accessed on 15 January 2012).

Olaizola M, La Roche J, Kolber Z, Falkowski PG (1994) Nonphotochemical fluorescence quenching and the diadinoxanthin cycle in a marine diatom. Photosynth Res 41: 357-370.

Olaizola M, Yamamoto HY (1994) Short-term response of the diadinoxanthin cycle and fluorescence yield to high irradiance in diatoms (Bacillariophyceae). J Phycol 30: 606-612.

Polimene L, Brunet C, Allen JI, Butenschon M, White DA, Llewellyn C (2012) Modelling xanthophyll photoprotective activity in photoplankton. J Plankt Res 34: 196-207.

Palmisano AC, SooHoo BJ, White DC, Smith GA, Stanton GR, Burckle LH (1985) Shade adapted benthic diatom beneath Antarctic sea ice. J Phycol 21: 554-667.

Post AF, Dubinsky Z, Wyman K, Falkowski PG (1984) Kinetics of light-intensity adaptation in a marine phytoplanktonic diatom. Mar Biol 83: 231-238.

Ragni M, D’alcalà MR (2007) Circadian variability in the photobiology of Phaeodactylum tricornutum: pigment content. J Plankt Res 29: 141-156.

Raven JA, Geider RJ (2003) Adaptation, acclimation and regulation in algal photosynthesis. In: Photosynthesis in algae (eds Larkum AW, Douglas SE, Raven JA). Kluwer Academic Publisher, Netherlands, pp. 365-412.

Scheer H. (2003) The pigments. In: Light-harvesting antennae in photosynthesis (eds Green BR, William WP). Kluwer Academic Publisher, Netherlands, pp. 29-81.

Shreve AP, Trautman JK, Owens TG, Alvrecht AC (1991) A femtosecond study of electronic state dynamics of fucoxanthin and implications for photosynthetic carotenoid-to-chlorophyll energy transfer mechanisms. Chem Phys 154: 171-178.

Stolte W, Kraay GW, Noordeloos AAM, Riegman R (2000) Genetic and physiological variation in pigment composition of Emiliania huxleyi (Prymnesiophyceae) and the potential use of its pigment ratios as a quantitative physiological marker. J Phycol 36: 529-539.

Sukenik A, Bennett J, Falkowski PG (1988) Changes in the abundance of individual apoproteins of light-harvesting chlorophyll $a / b$-protein complexes of Photosystem I and II with growth irradiance in the marine chlorophyte. Biochim Biophys Acta 932: 206-215.

Suzuki R, Ishimaru T (1990) An improved method for the determination of phytoplankton chlorophyll using $N, N$-demethylformamide. J Oceanogr 46: 190-194.

Yamamoto HY (1985) Xanthophyll cycles. Meth Enzymol 110: 303-312.

Young AJ, Phillip D, Ruban AV, Horton P, Frank HA (1997) The xanthophyll cycle and carotenoid-mediated dissipation of excess excitation energy in photosynthesis. Pure and Appl Chem 69: $2125-2130$. 